\title{
Analisis Hasil Percobaan Alat Praktikum Rugi-Rugi Aliran Dalam Pipa
}

\author{
Nefli Yusuf ${ }^{1}$, Hariadi $^{2}$ \\ Fakuktas Teknik Universitas Muhammadiyah Sumatera Barat ${ }^{1,2}$ \\ Email: nefli.yusuf@yahoo.co.id ${ }^{1}$, hariadi05@gmail.com ${ }^{2}$ \\ Doi: http://dx.doi.org/10.31869/rtj.v4i1.2315
}

\begin{abstract}
Abstrak: Fenomena aliran dalam pipa adalah salah satu percobaan yang dilakukan pada prakikum Fenomena Mesin di prodi Teknik Mesin.Pada makalah ini akan dikemukakan hasil percobaan dari alat yang untuk pertama kalinya dibuat di prodi Teknik Mesin UMSB. Pompa yang dipakai cukup besar 1,0 HP diharapkan akan terjadi tekanan yang cukup tinggi dan mengakibatkan aliran turbulen. Alat ukur yang dipasang adalah Pressure Gauge, Stopwatch, MeteranAir.Air dipompa dari sumber (reservoir) berupa bak ke jaringan pipa berdiameter 3/4", 1/2" dan 5/8" dengan memasang sensor tekanan pada keluaran pompa dan masing-masing pipa. Meteran air berguna untuk melakukan pengukuran laju kecepatan air, pada saat ini, yaitu dengan mengukur kapasitas keluaran $5 \mathrm{ml}$ yang selanjutnya diukur waktu yang diperlukan menggunakan stopwatch. Variasi laju aliran air dibuat dengan membedakan bukaan katup yaitu 4/4 bukaan total kemudian 3/4, 1/2 dan 1/4 . Hasil percobaan memperlihatkan bahwa semakin kecil bukaan katupmengakibatkan laju aliran semakin kecil mengakibatkan rugi-rugi aliran semakin besar. Pada kecepatan aliran semakin besar sehingga mengakibatkan Bilangan Reynold yang besar sedangkan rugi gesekan aliran tidak begitu berpengaruh karena aliran pada kondisi turbulen. Rancangan alat percobaan ini sudah sesuai dengan teori gesekan aliran fluida dalam pipa, aliran tertutup, untuk tahap berikutnya perlu pengembangan alat dengan memasukkan faktor/parameter panjang per diameter pipa sirkulasi, lebih lanjut untuk aliran laminar dimana sensitifitas bilangan Reynold lebih berpengaruh terhadap rugi-rugi gesekan untuk itu perlu alat ukur yang lebih presisi.
\end{abstract}

Kata Kunci: Fenomena aliran, rugi gesekan, bukaan katup, aliran tertutup.

\begin{abstract}
The phenomenon of flow in a pipe is one of the experiments carried out in the Mechanical Phenomenon Practicum in bachellor of Mechanical Engineering. In this paper, we will describe the experimental results of the tool that was made in mechanical engineering prgram, west sumatera muhammadiyah university for the first time. The pump used is large enough to $1.0 \mathrm{HP}$, it is expected that the pressure will be high enough and cause turbulent flow. Measuring instruments installed are Pressure Gauge, Stopwatch, and Water Meter. Water is pumped from the source (reservoir) in the form of a tub to a network of pipes with diameters of $3 / 4$ ", 1/2" and 5/8 "by installing pressure sensors at the pump output and each of pipe. The water meter is useful for measuring the rate of water, resulting in greater flow losses. At the greater the flow velocity, resulting in a large Reynolds Number, while the velocity, at this time, namely by measuring the output capacity of $5 \mathrm{ml}$ which is then measured the time needed using a stopwatch. The variation of the water flow rate is made by distinguishing the valve openings, namely $4 / 4$ total openings then $3 / 4,1 / 2$ and $1 / 4$. The experimental results show that the smaller the valve opening than the smaller the flow rateflow friction loss has not so effect because of the flow is in turbulent conditions. The design of this experimental tool is in compliance with the friction theory of fluid flow in pipes, closed flow, for the next stage it is necessary to develop a tool by entering the length per diameter factor (parameter)of the circulation pipe, further for laminar flow where the sensitivity of the Reynolds number has more effect on friction losses so need the precision measurement tools.
\end{abstract}

Keywords:flow phenomenon, friction loss, valve opening, closed flow. 


\section{PENDAHULUAN}

Dengan bertambahnya kemajuan teknologi di segala bidang menuntut kita untuk lebih mampu dalam penguasaanya maupun pemahamannya, yang lebih dititik beratkan sejauh mana kita bisa menguasai teknologi tersebut.Sistim aliran fluda dalam pipa banyak digunakan pada industri, seperti pengolahan air minum dan pembanguna pada gedung-gedung bertingkat.Sistem perpipaan ini meliputi pipa-pipa beserta komponenkomponennya yang dapat berupa suatu aliran tunggal, jaringan maupun sirkuit.Karakteristik sistem perpipaan dibutuhkan untuk rencana suatu sistem yang optimal.

Pada pengujian rugi aliran dalam pipa sirkulasi tertutup adalah sebagai berikut :

1. Berapa besar kecepatan aliran fluida (v) pada pipa sirkulasi tertutup?

2. Berapa bilangan Reynold dari pengujian alat pada sirkulasi tertutup?

3. Berapa besar faktor gesekan (f) major losses pada pipa sirkulasi tertutup?

Tujuan penelitian yang akan dicapai adalah sebagai berikut:

1. Untuk memperoleh pengertian tentang rugi aliran yang terjadi dalam aliran pipa.

2. Untuk menentukan jenis aliran dari hasil bilangan Reynold.

3. Untuk menentukan faktor gesek aliran dalam pipa.

Dalam penelitian ini manfaat yang dapat diambil adalah mengetahui rugi-rugi aliran pada pipa sirkulasi tertutup dengan menggunakan alat uji rugi aliran.

Penelitian ini dilakukan dengan menggunakan alat rugi-rugi aliran untuk menguji kerugian pada pipa, katup, pembesaran penampang, pengecilan penampang,yang akan di buat untuk kebutuhan pratikum di program studi Teknik Mesin UMSB.

\section{DASAR TEORI}

Rugi-rugi aliran adalah berkurangnya masa, volume dan kecepatan suatu fluida yang melewati suatu aliran. Dalam ilmu mekanika fluida kita kenal ada dua jenis kerugian head yaitu kerugian mayor (mayor head losses) dan kerugian minor (minor head losses). Pada penelitian ini seksi uji yang digunakan adalah pipa pvcdan percabangan (dividing) dari kecil ke besar muali dari sudut $90^{\circ}$ dan $180^{\circ}$. Kofisien kerugian total adalah penjumlahan antara koefisien kerugian tiap cabang. Nilai perbandingan hasil penelitian untuk hubungan koefisien kerugian (ktotal) dengan perubahan sudut cabang ( $a$ ) dengan peneliti sebelumnya diberikan peningkatan seiring dengan kenaikan sudut cabang ( $\alpha$ ).Hal ini disebabkan karena semakin besar sudut pada percabangan maka semakin besar tahanannya.Pada percabangan maka semakin besar nhjkpula nilai koefisien totalnya. Hal ini juga diinformasikan pada hasil penelitian sebelumnya dengan menggunakan percabangan "Lateral Dividing Branch" dimana menunjukkan kesimpulan yang sama.

Aliran fluida sangat bergantung dari kecepatan aliran fluida, semakin tinggi kecepatan akan mempengaruhi pola aliran, kondisi aliran akan berubah dari laminar menjadi turbulen. Besaran yang dapatmenghubungkan antara kecepatan aliran, kondisi fluida dan kondisi penampang diameter pipa adalah angka Reynolds (Sularso, 1994). Jenis-jenis aliran tersebut terbagi menjadi 3 jenis aliran yaitu

\section{a. Aliran Laminar}

Aliran laminar adalah aliran fluida yang bergerak dalam lapisan-lapisan dengan satu lapisan meluncur dengan lancar.Aliran laminar merupakan aliran yang jarang terjadi pada air dan tidak begitu penting dalam aliran fluida atau udara, tapi ini terjadi dalam viscosity fluida yang tinggi seperti campuran sediment dalam air,es, dan lava.

\section{b. Aliran turbulen}

Aliran turbulen adalah aliran dimana pergerakan dari partikel-partikel suatu fluida tidak menentu karena mengalami percampuran serta putaran partikel antar lapisan, yang kemudian mengakibatkan saling tukar momentum dari suatu bagian fluida ke bagian fluida yang lainnya dalam skala yang besar.Pada aliran turbulen, massa air bergerak keatas, kebawah, dan secara lateral berhubungan dengan arah arus yang umum, memindahkan massa dan momentum.

\section{c. Aliran transisi}

Aliran transisi adalah aliran peralihan dari aliran laminar ke aliran turbulen. Keadaan peralihan ini tergantung pada viskositas suatu fluida, kecepatan fluida dan hal-hal lain yang berkaitan dengan geometri aliran, dimana aliran ini memiliki nilai bilangan Reynold antara 2300 sampai 4000

$(2300<\operatorname{Re}<4000)$.

Mayor Losses adalah kerugian pada aliran dalam pipa yang disebabkan oleh friction (gesekan) yang terjadi sepanjang aliran fluida yang mengalir terhadap dinding pipa.

Kerugian tekan (head loss) adalah salah satu kerugian yang tidak dapat dihindari pada satu aliran fluida yang berupa berkurangnya tekanan 
pada suatu aliran, sehingga menyebabkan kecepatan aliran mengecil. Salah satu kerugian yang sering terjadi dan tidak dapat diabaikan pada aliran air yang menggunakan pipa adalah kerugian tekan akibat gesekan dan perubahan penampang atau pada belokan pipa yang menggangu aliran normal

Persamaan dasar dalam hidrodinamika telah dapat dirintis dan dirumuskan oleh Bernoulli secara baik, sehingga dapat dimanfaatkan untuk menjelaskan gejala fisis yang berhubungan dengan aliran air.Persamaan dasar tersebut disebut sebagai persamaan Bernoulli atau teorema Bernoulli, yakni suatu persamaan yang menjelaskan berbagai hal yang berkaitan dengan kecepatan, tinggi permukaan zat cair dan tekanannya.Permasalahan aliran fluida dalam pipa dapat diselesaikan dengan menggunakan persamaan Bernoulli.

$$
\mathrm{p}+1 / 2 \rho \mathrm{v}^{2}+\rho \mathrm{gh}=\text { konstan }
$$

dimana $\mathrm{v}$ adalah kecepatan fluida, $\mathrm{g}$ adalah percepatan gravitasi bumi, $\mathrm{h}$ adalah ketinggian relatif terhadapa suatu referensi, $\mathrm{p}$ adalah tekanan fluida, $\rho$ adalah densitas fluida.

Untuk sistem perpipaan yang fluidanya liquid umumnya dari lokasi awal fluida, dipasang saringan untuk menyaring kotoran agar tidak menyumbat aliran fluida.Saringan dilengkapi dengan katup searah (foot valve) yang fungsinya mencegah aliran kembali ke lokasi awal atau tandom.Sambungan (fitting) adalah salah satu komponen pemipaanyang memiliki fungsi untuk merubah aliran, menyebarkan aliran, membesar atau mengecilkan aliran. Fitting merupakan salah satu komponen utama dalam pemipaan, Jenis-jenis sambungan (fitting)

Sedangkan sambungan digunakan untuk keperluan tekanan yang naik turun secara terus menerus karena akan terpengaruh terhadap kemampuan katup untuk menutp dengan rapat. Setiap katup yang digunakan untuk isolasi harus tersedia segel positif yangdapat diandalkan ketika menutup isolasi pabrik/sistem produksi terhadap jalannya sistem tersebut hanya diizinkan ketika risiko terhadap penghentian dan pengurangan tekanan sistem tidak dapat dihindari.

Menurut Triatmojo 1996, Pada zat cair ideal alirannya melalui bidang batas mempunyai distribusi kecepatan merata.Sedang pada zat cair riil, karena adanya pengaruh kekentalan, Kecepatan di daerah dekat bidang batas mengalami perlambatan dan pada bidang batas kecepatan adalah nol. Lapis zat cair di dekat bidang batas dimana pengaruh kekentalan dominan disebut dengan lapis batas.

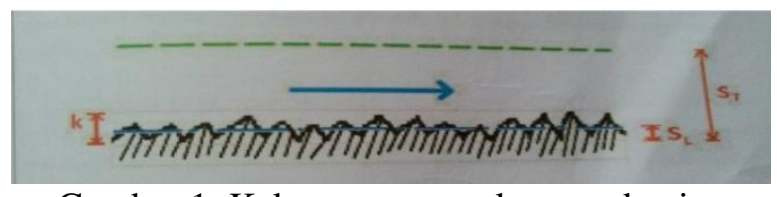

Gambar 1. Kekasaran permukaan pada pipa

Kehilangan energi akibat gesekan disebut juga kehilangan energi primer, energi primer terjadi akibat adanya kekentalan zat cair dan turbulensi karena adanya kekasaran dinding batas pipa dan akan menimbulkan gaya gesek yang akan menyebabkan kehilangan energi disepanjang pipa dengan diameter konstan pada aliran seragam.

Katup penutup atau isolasi tidak boleh dapat berupa sambungan penampang tetap, sambungan

penampang berubah, belokan (elbow) atau sambungan bentuk $\mathrm{T}(\mathrm{Tee})$ seperti gambar dibawahini.

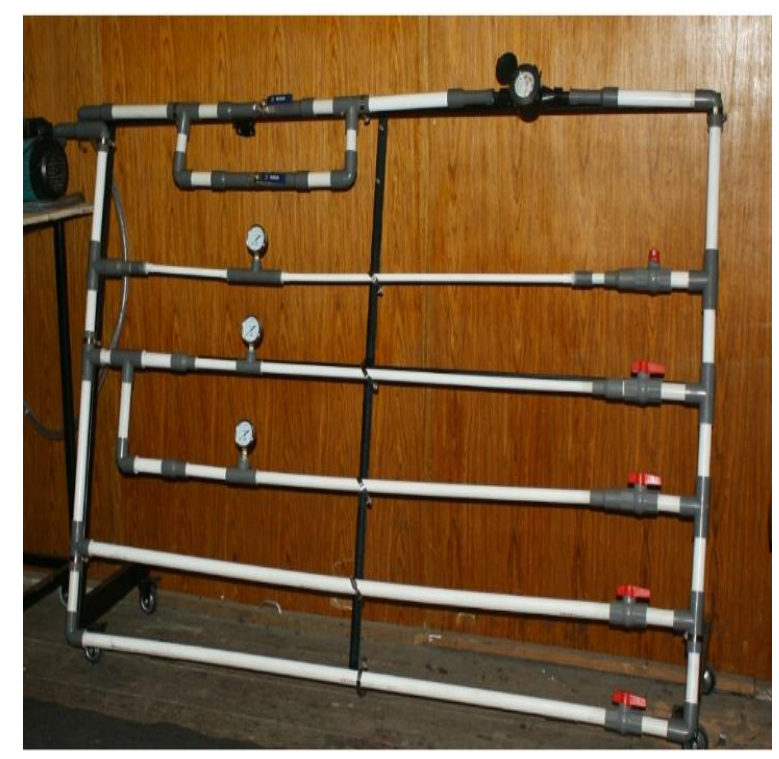

Gambar 2. Sistim Pemipaan

Gate valve mudah dikenali karena mempunyai body dan sistem yang panjang kegunaan utama dari gate valve adalah hanya untuk menutup dan membuka aliran.Gate valve tidak bisa digunakan untuk mengatur besar kecilnya aliran (regulate atau trotthling).

Globe valve merupakan salah satu jenis valve yang dirancang untuk mengatur besarkecilnya aliran fluida (regulate atau trotthling). Pada dasarnya bagian utama dari Globe valve ini sama saja dengan Gate valve. Yaitu terdiri dari body, seat, disc, bonnet, stem, packing dan gland.Globe valve dengan gate valve bentuknya hampir sama, tetapi ada ciri-ciri tertentu yang dapat dijadikan acuan untuk membedakan antara keduanya. 
Aliran melalui weir (saluran terbuka atau bendungan) dapat dianalisa dengan mengabaikan gesekan.Weir bertakik-V sering dipergunakan untuk pengukuran kapasitas kecil.

Orifice adalah sebuah plat lubang yang digunakan untuk mengukur laju aliran fluida. Menggunakan prinsip yang sama sebagai venturi nozzle, yaitu prinsip bernauli yang menyatakan bahwa ada hubungan antara tekanan fluida dan kecepatan. Ketika meninggalan kecepatan, tekanan berkurang dan sebaliknya.

Arus nozel merupakan arus yang sering digunakan sebagai tolok elemen untuk udara dan aliran gas dalam aplikasi industri.Penelitian ini dilakukan untuk mengetahui pengaruh diameter nozel terhadap tegangan maksimum yang terjadi.

\section{METODELOGI PENELITIAN}

Diagram Alir PembuatanAlat Uji Rugi-Rugi Aliran

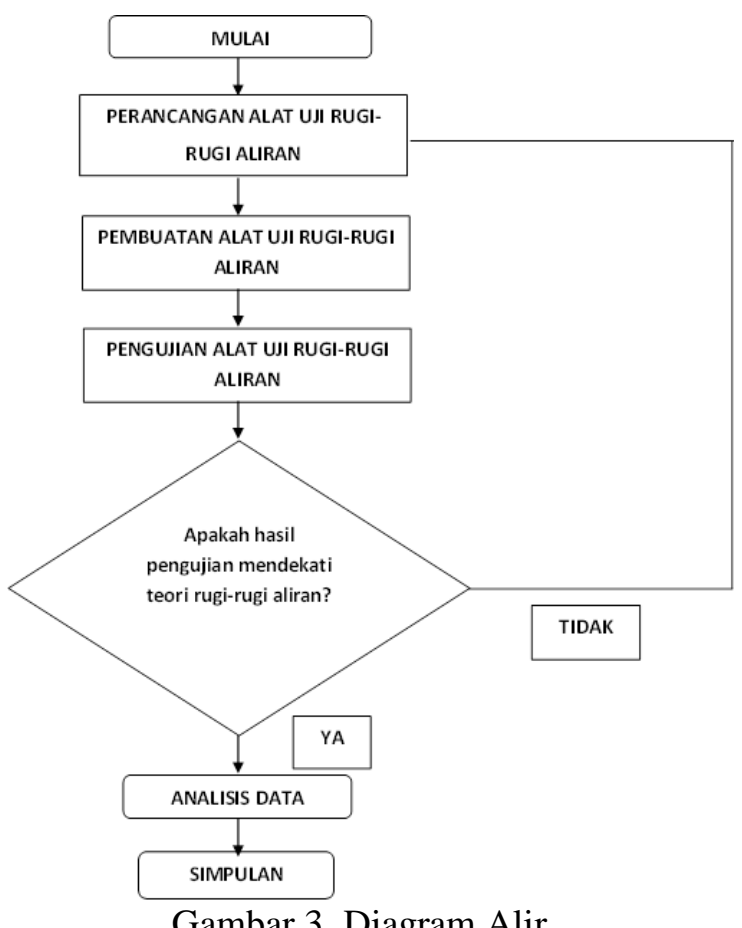

Adapun alat yang digunakan yaitu:

1. Pressure gauge

2. Stopwatch

3. Jangka sorong

4. Meteran

5. Pompa

6. Meteran Air (flow Meter)

Adapun bahan yang digunakan yaitu:

1. Pipa PVC

2. Elbow

3. Katup (Ball Valve)

4. Bak Penampung
5. Besi(Hollow)

6. Roda Troli

\section{HASIL DAN PEMBAHASAN}

Dari Pengujian alat rugi aliran diperoleh hasil data Tabel di bawah ini:

Tabel.1 Data Pipa Diametr 5/8"

\begin{tabular}{|c|c|c|c|c|c|}
\hline & & {$[\mathrm{psi}]$} & $\begin{array}{c}{\left[\mathrm{kg} / \mathrm{cm}^{2}\right.} \\
]\end{array}$ & $\begin{array}{c}{[\mathrm{cc}] /[\mathrm{ml}} \\
]\end{array}$ & {$[\mathrm{dt}]$} \\
\hline no. & $\begin{array}{c}\text { bukaa } \\
\mathrm{n}\end{array}$ & $\begin{array}{c}\mathrm{P} \\
\text { pomp } \\
\mathrm{a}\end{array}$ & p pipa & $\begin{array}{c}\text { meter } \\
\text { air }\end{array}$ & $\mathrm{t}$ \\
\hline 1 & $4 / 4$ & 10 & 0,35 & 5 & $\begin{array}{c}14,3 \\
8\end{array}$ \\
\hline 2 & $3 / 4$ & 11 & 0,4 & 5 & 14,5 \\
\hline 3 & $2 / 4$ & 12 & 0,5 & 5 & $\begin{array}{c}14,9 \\
6\end{array}$ \\
\hline 4 & $1 / 4$ & 24 & 2,2 & 5 & $\begin{array}{c}20,6 \\
8\end{array}$ \\
\hline
\end{tabular}

Tabel.2 Data Pipa Diameter 1/2"

\begin{tabular}{|c|c|c|c|c|c|}
\hline & & {$[\mathrm{psi}]$} & $\begin{array}{c}{\left[\mathrm{kg} / \mathrm{cm}^{2}\right.} \\
]\end{array}$ & $\begin{array}{c}{[\mathrm{cc}] /[\mathrm{ml}} \\
]\end{array}$ & {$[\mathrm{dt}]$} \\
\hline no & $\begin{array}{c}\text { bukaa } \\
\mathrm{n}\end{array}$ & $\begin{array}{c}\mathrm{P} \\
\text { pomp } \\
\text { a }\end{array}$ & p pipa & $\begin{array}{c}\text { meter } \\
\text { air }\end{array}$ & t \\
\hline 1 & $4 / 4$ & 9 & 0,2 & 5 & 14,09 \\
\hline 2 & $3 / 4$ & 10 & 0,25 & 5 & 14,22 \\
\hline 3 & $2 / 4$ & 10 & 0,5 & 5 & 14,44 \\
\hline 4 & $1 / 4$ & 30 & 1,92 & 5 & 16,85 \\
\hline
\end{tabular}

Tabel.3 Data Pipa Diametr 3/4"

\begin{tabular}{|c|c|c|c|c|c|}
\hline & & {$[\mathrm{psi}]$} & $\begin{array}{c}{[\mathrm{kg} / \mathrm{cm}} \\
2]\end{array}$ & $\begin{array}{c}{[\mathrm{cc}] /[\mathrm{m}} \\
1]\end{array}$ & {$[\mathrm{dt}]$} \\
\hline $\begin{array}{c}\text { no } \\
\cdot\end{array}$ & $\begin{array}{c}\text { bukaa } \\
\mathrm{n}\end{array}$ & $\begin{array}{c}\mathrm{P} \\
\text { pomp } \\
\mathrm{a}\end{array}$ & p pipa & $\begin{array}{c}\text { meter } \\
\text { air }\end{array}$ & $\mathrm{T}$ \\
\hline 1 & $4 / 4$ & 10 & 0,3 & 5 & 13,95 \\
\hline 2 & $3 / 4$ & 10 & 0,25 & 5 & 14,05 \\
\hline 3 & $2 / 4$ & 11 & 0,4 & 5 & 14,20 \\
\hline 4 & $1 / 4$ & 12 & 1,5 & 5 & 16,34 \\
\hline \multicolumn{5}{|c|}{ Penurunan rumus Hukum } \\
\end{tabular}

$p+1 / 2 \rho v^{2}+\rho g h=$ konstan, dimana $v$ adalah kecepatan fluida, $\mathrm{g}$ adalah percepatan gravitasi bumi, $\mathrm{h}$ adalah ketinggian relatif terhadapa suatu referensi, $p$ adalah tekanan fluida, $\rho$ adalah densitas fluida.

Turunan rumus Bernaulli asumsi parameter yang dipakai:

$$
\mathrm{P}_{1}+\frac{\rho \mathrm{V}_{2}{ }^{\mathrm{x}}}{2}+\rho \mathrm{gh}_{1}=\mathrm{P}_{2}+\frac{\rho \mathrm{NV}_{2}{ }^{2}}{2}+\rho \mathrm{gh}_{2}+\mathrm{f}(\text { gesekan })
$$




$$
\mathrm{f}=\mathrm{p}_{1}-\mathrm{p}_{2}+\frac{\rho}{2}\left(\mathrm{v}_{1}^{2}-\mathrm{v}_{2}^{2}\right)+\rho \mathrm{g}\left(\mathrm{h}_{1}-\mathrm{h}_{2}\right)
$$

asumsi:

$$
\begin{aligned}
& \mathrm{v}=\mathrm{v}_{1}-\mathrm{v}_{2}(\mathrm{v} \text { dalam pipa }) \\
& \Delta h=\mathrm{h}_{1}-\mathrm{h}_{2} \\
& \Delta p=\mathrm{P} \text { pompa }-\mathrm{P} \text { pipa } \\
& \quad \mathrm{f}=\Delta p+\frac{\rho}{2} V^{2}+p g\left(\mathrm{~h}_{2}-\mathrm{h}_{1}\right) \\
& \mathrm{p} \frac{\mathrm{v}^{2}}{2}=\frac{k}{2}\left(\frac{g}{A}\right)^{2} \quad \mathrm{~A}=\frac{\pi d^{2}}{4} \\
& \mathrm{k}=\frac{\rho}{2} \cdot\left(\frac{4}{\pi d^{2}}\right)^{2} \\
& \mathrm{v}=\frac{Q}{A} \mathrm{Q}=\mathrm{v} \cdot \mathrm{a} \\
& \mathrm{f}=\Delta \mathrm{p}+\mathrm{kQ} \mathrm{Q}^{2}+\Delta \mathrm{h}
\end{aligned}
$$

dimana $\Delta \mathrm{p}$ adalah Tekanan, $\mathrm{kQ}^{2}$ adalah Kecepatan, $\Delta \mathrm{h}$ Adalah Ketinggian.

Tabel dan grafik Hasil pengolahan data rugi gesekan vs laju aliran pada pipa 5/8",1/2",3/4".

Tabel.4 Hasil Pengujian Pipa Diameter 5/8"

\begin{tabular}{|c|c|c|c|}
\hline NO & Bukaan & q (laju) & $\mathrm{f}($ gesekan) \\
\hline 1 & $4 / 4$ & 3,477051 & 5,77732 \\
\hline 2 & $3 / 4$ & 3,448276 & 12,6808 \\
\hline 3 & $2 / 4$ & 3,342246 & 20,03 \\
\hline 4 & $1 / 4$ & 2,417795 & 104,565 \\
\hline
\end{tabular}

Gravik.1 Hasil pengolahan data rugi gesekan vs laju aliran pada pipa diameter $5 / 8$ ".

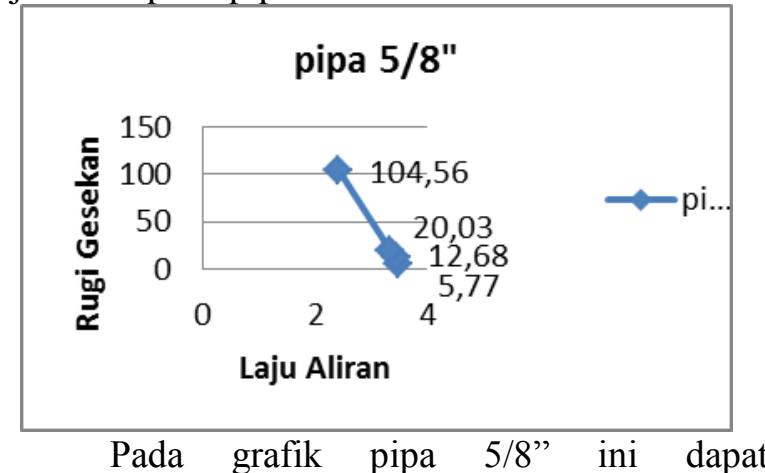

disimpulkan bawha semakin kecil pipa yang digunakan semakin tinggi laju alirannya tetapi, rugi gesekan pada pipanya rendah, untuk bukaan katup 4/4 sampai 2/4 laju alirannya tinggi sementara rugi gesekannya rendah, ketika katup diposisikan pada bukaan 1/4 maka laju alirannya turun drastis sementara itu gesekan pada pipa naik drastis

Tabel.5 Hasil Pengujian Pipa Diameter 1/2"

\begin{tabular}{|c|c|c|c|}
\hline NO & Bukaan & Q (laju) & f (gesekan) \\
\hline 1 & $4 / 4$ & 1,77431 & 9,59521 \\
\hline
\end{tabular}

\begin{tabular}{|c|c|c|c|}
\cline { 3 - 4 } 2 & $3 / 4$ & 1,75809 & 16,3384 \\
\hline 3 & $2 / 4$ & 1,7313 & 16,1201 \\
\hline 4 & $1 / 4$ & 1,48368 & 150,246 \\
\hline
\end{tabular}

Grafik.2 Hasil pengolahan data rugi gesekan vs laju aliran pada pipa diameter $1 / 2$ ".

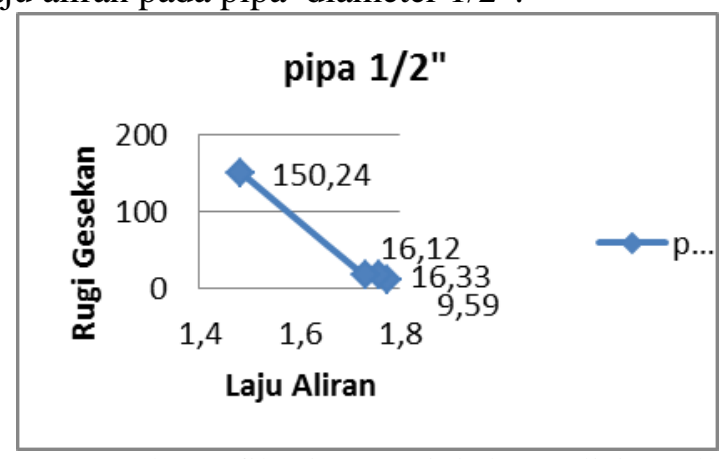

Pada grafik pipa 1/2 ini dapat disimpulkan bahwa semakin besar ukuran pipa yang digunakan maka semakin kecil laju alirannya, tetapi rugi gesekan pada pipa tinggi, untuk bukaan katup 4/4 sampai $2 / 4$ laju alirannya tinggi sementara rugi gesekannya rendah, ketika katup diposisikan pada bukaan 1/4 maka laju alirannya turun drastis sementara itu gesekan pada pipa naik drastis.

Tabel.6 Hasil Pengujian Pipa Diameter 3/4"

\begin{tabular}{|c|c|c|c|}
\hline NO & Bukaan & Q (laju) & $\begin{array}{c}\mathrm{f} \\
\text { (gesekan) }\end{array}$ \\
\hline 1 & $4 / 4$ & 1,792115 & 16,77874 \\
\hline 2 & $3 / 4$ & 1,779359 & 16,73667 \\
\hline 3 & $2 / 4$ & 1,760563 & 23,46201 \\
\hline 4 & $1 / 4$ & 1,529988 & 117,1867 \\
\hline
\end{tabular}

Grafik.3 Hasil pengolahan data rugi gesekan vs laju aliran pada pipa diameter $3 / 4 "$.

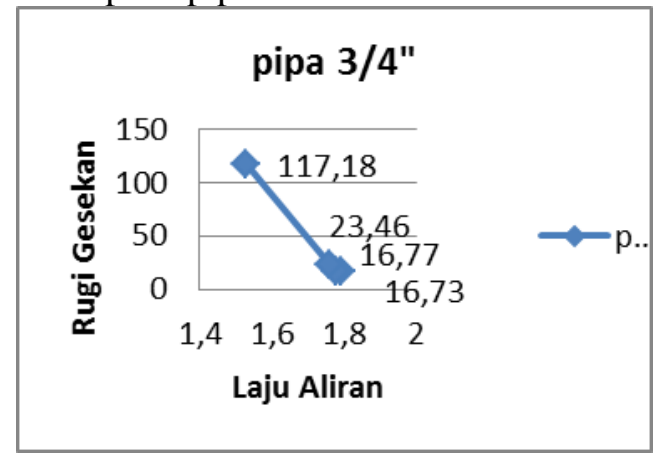

Pada Grafik pipa 3/4 ini dapat disimpulkan bawhwa semakin besar ukuran pipa yang digunakan maka semakin kecil laju alirannya, tetapi rugi gesekan pada pipa tinggi, untuk bukaan katup 4/4 sampai 2/4 laju alirannya tinggi sementara rugi gesekannya rendah, ketika katup diposisikan pada bukaan 1/4 maka laju alirannya 
turun drastis sementara itu gesekan pada pipa naik drastis.

Untuk membedakan aliran apakah turbulen laminar dan transisi, kita harus menentukan Angka Reynold (Reynolds Number). Angka ini dihitung dengan persamaan sebagai berikut:

$$
\operatorname{Re}=\frac{\rho v L}{\mu}=\frac{v L}{v}=\frac{\text { Gayainersia }}{\text { Gayaviskos }}
$$

Dimana Re adalah Angka Reynold (tanpa satuan), V adalah Kecepatan fluida (ft/s atau m/s), $\mathrm{L}$ adalah Panjang karakteristik, $\mu$ adalah Viskositas kinematis,tabel sifat cairan (ft/s atau $\mathrm{m}^{2} / \mathrm{s}$ ), $\rho$ adalah Kerapatan (densitas) Fluida.

$$
\begin{aligned}
& \operatorname{Re}=\frac{\rho v L}{\mu L}=\frac{v L}{v}=\frac{\text { Gaya inersia }}{\text { Gaya viskos }} \\
& \operatorname{Re}=\frac{V L}{\mu}
\end{aligned}
$$

Dimana $V$ adalah Kecepatan, $L$ adalah Panjang pipa, $\mu$ adalahkoefisien viskos untuk aliran air.

Menentukan jenis aliran denganhasil bilangan Reynold dengan diagram moody

Tabel.7 Hasil Bilangan Reynold Pipa Dimeter $5 / 8$ "

\begin{tabular}{|c|c|c|c|}
\hline $\mathrm{q}$ & $\mathrm{V}$ & $\mathrm{Re}$ & $\mathrm{F}$ \\
\hline 3,477051 & 1,531875 & 3045478 & 5,77732 \\
\hline 3,448276 & 1,519198 & 3020274 & 12,6808 \\
\hline 3,342246 & 1,472484 & 2927404 & 20,03 \\
\hline 2,417795 & 1,065201 & 2117697 & 104,565 \\
\hline
\end{tabular}

Tabel.8 Hasil Bilangan Reynold Pipa Diameter $1 / 2 "$

\begin{tabular}{|c|c|c|c|}
\hline $\mathrm{q}$ & $\mathrm{V}$ & $\mathrm{Re}$ & $\mathrm{f}$ \\
\hline 1,774308 & 0,46676 & 927952,6 & 9,59521 \\
\hline 1,758087 & 0,462493 & 919469,2 & 16,3384 \\
\hline 1,731302 & 0,455447 & 905460,7 & 16,1201 \\
\hline 1,48368 & 0,390306 & 775955,6 & 150,246 \\
\hline
\end{tabular}

Tabel.9. Hasil Bilangan Reynold Pipa Diameter $3 / 4$ "

\begin{tabular}{|c|c|c|c|}
\hline $\mathrm{Q}$ & $\mathrm{V}$ & $\mathrm{Re}$ & $\mathrm{f}$ \\
\hline 1,79211 & 0,33754 & 671060 & 16,7787 \\
\hline 1,77936 & 0,33514 & 666284 & 16,7367 \\
\hline 1,76056 & 0,3316 & 659245 & 23,462 \\
\hline 1,52999 & 0,28817 & 572906 & 117,187 \\
\hline
\end{tabular}

Moddy Diagram

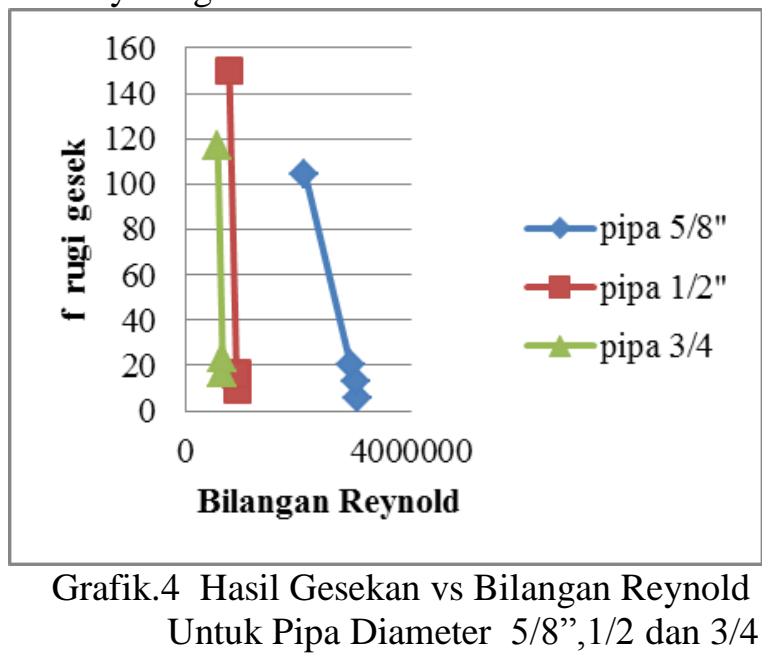

Bilangan Reynold untuk pipa 5/8" berubah lebih besar dibanding pipa $1 / 2$ " dan $3 / 4$ " sementara untuk bukaan $1 / 4$ juga berubah lebih besar dibandingkan dengan bukaan $1 / 2,3 / 4$ dan 4/4. Semakin kecil diameter pipa mengakibatkan semakin besar laju/kecepatan aliran sementara semakin kecil buaan katup mengakibatkan laju/kecepatan aliran semakin kecil pula. Hal ini mengakibatakn rugi-rugi gesekan semakin besar sementara laju dan kecepatan yang besar mengakibatkan bilangan Reynold yang besar. Fenomena ini sudah sesuai dengan teori tetapi kenaikan rugi-rugi aliran yang signifikan untuk bukaan katup 1/4" dan kenaikan bilangan Reynold untuk pipa diameter 5/8" yang signifikan barangkali perlu analisa lebih lanjut. 


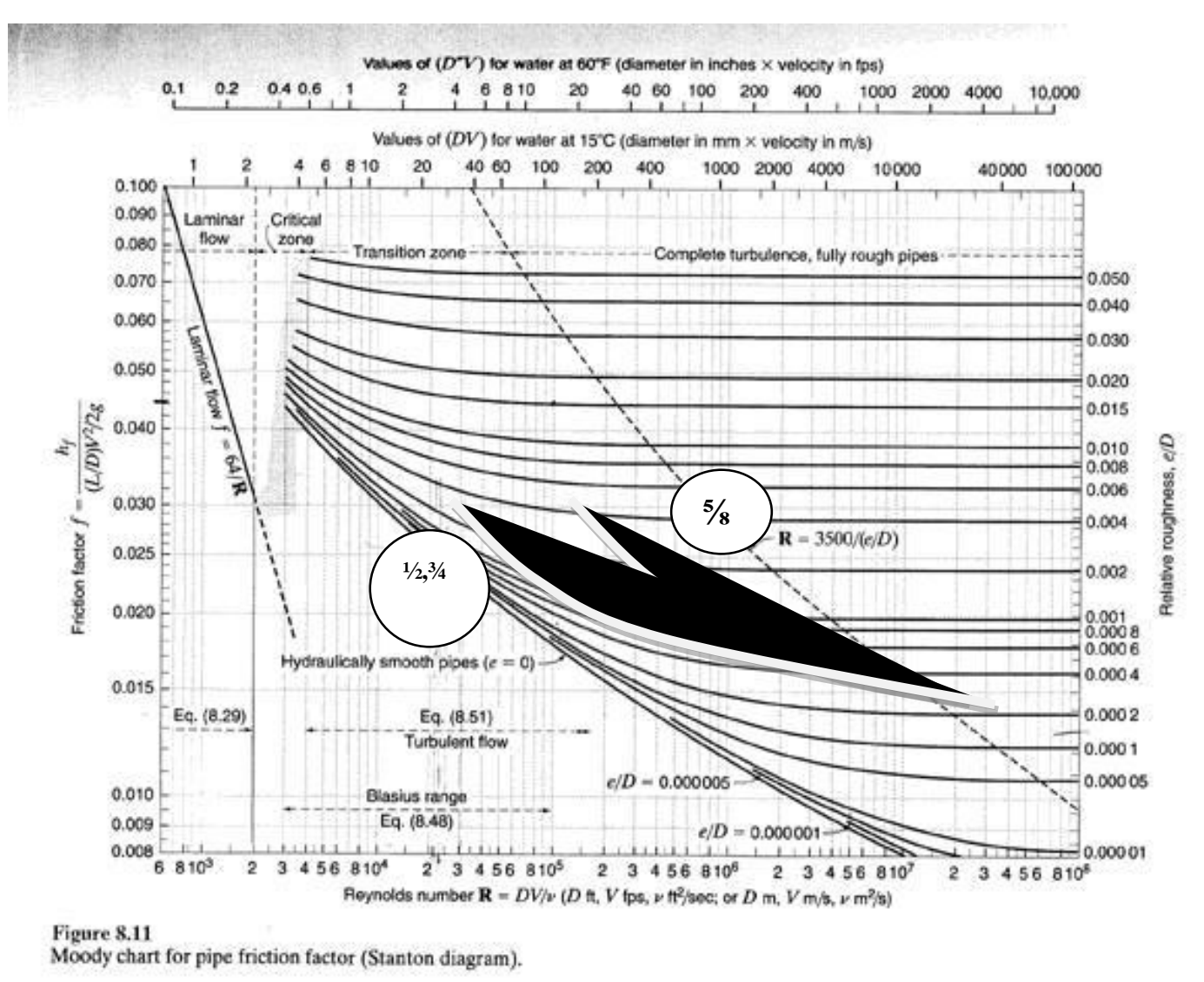

Grafik.5Plot koefisien rugi aliran pipa 5/8",1/2",3/4" pada diagram Moddy

Hasil plot koefisien rugi aliran dalam pipa 5/8",1/2",3/4",dapatterilihatpada daerah bilangan Reynold yang tinggi dimana pada daerah ini terjadi aliran turbulan. Seandainya rancangan dilakukan untuk laju/kecepatan aliran dengan kata lain bilangan Reynold yang kecil akan terlihat kenaikan rugi-rugi aliran yang besar, untuk pengembangan alat berikutnya barangkali hal ini juga dilakukan.

\section{PENUTUP}

1. Pengukuran kerugian aliran dalam pipa dapat ditentukan dengan mengukur head tekanan, kecepatan dan keinggian pada dua sisi pipa yang diamati, Ketinngian pada pipa tidak terlalu berpengatuh karena pipa diletakkan mendatar.

2. Semakin kecil bukaan katup semakin keci laju/kecepatan aliran dan semakin tinggi rugi-rugi aliran, ada kenaikan rugi-rugi aliran yang cukup signifikan untuk bukaan $1 / 4$, sementara rugi-rugi aliran untuk bukaan 2/4 dan 3/4 tidak begitu signifikan.

3. Semakin rendah laju/kecepatan aliran mengakibatkan semakin besar rugi-rugi aliran, dimana laju/kecepatan aliran berbanding lurus dengan bilangan Reynold sehingga kecenderungannya sudah sesuai dengan diagram Moody.

4. Hasil Plot nilai rugi-rugi aliran terhadap diagram Moody dapat terlihat bahwa aliran berada pada daerah aliran turbulen.

5. Dalam pengujian yang harus diperhatikan adalah kepresisian alat ukur yang digunakan saat melakukan uji praktikum.

6. Bagi para penelitiyang tertarik pada bidang kajian ini disarankan untuk dapat menindaklanjuti penelitian ini dengan memperhatikan perbandingan diameter pipa terhadap panjang pipa yang diukur perubahan tekanannya.

7. Perlu jugaa pengembangan terhadap fenomena aliran laminar, kemudian variasi kekasaran permukaan dalam pipa.

\section{DAFTAR PUSTAKA}

1. Munson, Bruce.R, Okiishim Theodore.H, Huebsch, WadeW., and Rothmayer, Alric.H; 2013, Fudamental of Fluid Mechanics, 7th edition, John Wiley \&Sons, Inc.

2. White Frank M., Fluid Mechanics, 5th edition, McGrowHill, 
3. Ranald V. Giles. 1996. mekanika fluida dan hidraulika penerjemah Ir. Herman widodo soemitro. Jakarta. Erlangga.

4. Victor L. Steeter dan E. Benjamin Wyle. 1988. Mekanika Fluida. Jakarta. Erlangga.
5. Austin H. Church. 1986. Pompa dan blower sentrifugal penerjemah Ir. Zulkifli Harahap. Jakarta. Erlangga. 